\title{
Treatment of Distal Anterior Cerebral Artery Aneurysms with Flow-Diverter Stents: A Single-Center Experience
}

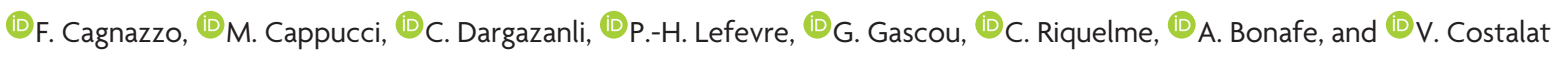

\begin{abstract}
BACKGROUND AND PURPOSE: Flow diversion for aneurysms beyond the circle of Willis is still debated. Our aim was to evaluate the safety and efficacy of flow diversion treatment of distal anterior cerebral artery aneurysms.
\end{abstract}

MATERIALS AND METHODS: Consecutive patients with distal anterior cerebral artery aneurysms treated from January 2014 to October 2017 were evaluated retrospectively with prospectively maintained data. Treatment was performed only for unruptured or recanalized aneurysms after coiling. Technical feasibility, procedural complications, aneurysm occlusion (O'Kelly-Marotta grading scale), and clinical outcome were evaluated.

RESULTS: Fifteen patients were included in the study, with 17 distal anterior cerebral artery saccular aneurysms treated with flow-diverter stents. Mean aneurysm size was $4.25 \pm 3.9 \mathrm{~mm}$; range, 2-9 mm. Flow diversion was used as retreatment among 6 previously coiled aneurysms ( 5 ruptured and coiled in the acute phase, and 1 unruptured and recanalized). Stent deployment was technically successful in all cases. During the perioperative period, 1 patient experienced a transient minor stroke (6\%), whereas 2 patients reported acute in-stent thrombosis with disabling ischemic complications (13\%). Fourteen patients and 16 aneurysms were available during a mean radiologic follow-up of 12 months (range, 3-24 months). Overall, 12 (75\%) aneurysms were completely occluded (O'Kelly-Marotta grading scale score D), 1 aneurysm (6\%) showed near-complete occlusion (O'Kelly-Marotta grading scale score C), and 3 aneurysms (19\%) were incompletely occluded (O'Kelly-Marotta grading scale, score B). All 6 aneurysms previously coiled were completely occluded after flow diversion, whereas $70 \%$ of aneurysms treated with flow diverters alone showed complete/near-complete occlusion (O'Kelly-Marotta grading scale C-D). There were no cases of aneurysm rupture, in-stent occlusion, or retreatment during long-term follow-up.

CONCLUSIONS: Treatment of distal anterior cerebral artery aneurysms with flow-diverter stents is feasible and effective, with high rates of aneurysm occlusion. Flow diversion plus coiling, in the retreatment of lesions previously coiled, allowed higher rates of occlusion compared with flow diverters alone. However, the risk of ischemic complications is not negligible, and flow-diversion treatment should be evaluated only for aneurysms not amenable to simple coil embolization.

ABBREVIATIONS: $\mathrm{ACA}=$ anterior cerebral artery; $\mathrm{OKM}=$ O'Kelly-Marotta grading scale

A neurysms arising from the anterior cerebral artery (ACA) distal to the anterior communicating artery complex account for 5\%$10 \%$ of all intracranial aneurysms. ${ }^{1,2}$ The distal access, the small caliber of the parent artery, and the frequency of wide-neck lesions are factors that contribute to the complexity of coiling, stent-assisted coiling, and remodeling techniques in distal ACA lesions. ${ }^{3,4}$ In addi-

Received November 28, 2017; accepted after revision February 6, 2018.

From the Neuroradiology Department, University Hospital Güi-de-Chauliac, Centre Hospitalier Universitaire de Montpellier, Montpellier, France.

Please address correspondence to Federico Cagnazzo, MD, Neuroradiology Department, CHU Gui De Chauliac, 80 Ave Augustin Fliche, 34000 Montpellier, France; e-mail: f.cagnazzo86@gmail.com

三 Indicates article with supplemental on-line tables.

http://dx.doi.org/10.3174/ajnr.A5615 tion, due to the deep-seated location in the interhemispheric fissure, clip reconstruction or in situ bypass through an interhemispheric approach is technically challenging. ${ }^{5}$ Based on their ability to reconstruct the parent artery, the off-label uses of flow-diverter stents are constantly extended, including aneurysms in distal locations and with unfavorable anatomy. Recently, the use of flow diversion in distal ACA aneurysms has been reported as an alternative treatment for lesions difficult to treat with conventional endovascular or surgical strategies. However, few publications have reported treatment-related outcomes of flow diversion in this location, and the efficacy and safety of this technique remain unclear. $^{6-15}$

We present a retrospective series of 15 consecutive patients with 17 distal ACA aneurysms treated with flow-diverter stents at 
our institution. In addition, we discuss the safety and efficacy of this treatment, comparing our experience with the results reported in the literature.

\section{MATERIALS AND METHODS \\ Patient Selection}

Our hospital institutional review board approved this retrospective study. The prospectively maintained data bases at our institution were retrospectively reviewed by 2 and, in case of inconsistency, by 3 investigators independently to identify patients with distal ACA aneurysms treated with flow-diverter stents between January 2014 and October 2017. Data collection included the following: demographics, aneurysm characteristics, diameter of the parent artery and ACA branches covered with the stent, details of the endovascular treatment, clinical presentation, follow-up imaging, and clinical outcome. Treatment strategy was made by multidisciplinary consensus (vascular neurosurgeons, interventional neuroradiologists). The decision to treat with flow-diverter stents was made on the basis of the following: 1) the presence of a wide neck, 2) a branching vessel coming from the aneurysm that could result in the coil falling out of the aneurysm into the branch, 3) recanalization of aneurysm incompletely occluded with previous coiling because of the unfavorable anatomy, and 4) unstable position of the microcatheter inside the aneurysm during coiling due to the distal location and tortuosity of the ICA.

\section{Antiplatelet Therapy}

The standard antiplatelet therapy included daily dual-antiplatelet medication with aspirin (Kardegic), $75 \mathrm{mg}$, and clopidogrel (Plavix), $75 \mathrm{mg}$, starting no less than 5 days before the treatment. In general, the therapy was maintained for a minimum of 6 months until the first clinical and radiologic follow-up. After 6 months, based on the clinical and radiologic evaluation, the patients were switched to $75 \mathrm{mg}$ of aspirin for a minimum of 6 months or for life. Aspirin was continued after 1 year in case of flow reduction of the covered branch or in case of luminal narrowing related to the intimal hyperplasia; meanwhile, aspirin was stopped after the 1-year follow-up in case of incomplete aneurysm occlusion with the aim of improving the thrombosis of the aneurysm dome. VerifyNow P2Y12 assay (Accumetrics, San Diego, California) was used to test the platelet inhibition. In case of platelet inhibition of $<40 \%$, an additional loading dose of clopidogrel, $300 \mathrm{mg}$, or prasugrel, 10-20 mg, was administered before the procedure. Concurrent with the procedure, intravenous heparinization was performed (activated clotting time maintained above 250 seconds).

\section{Description of Technique}

All patients were treated under general anesthesia via a transfemoral approach. Access to the distal ACA was obtained in a triaxial fashion. Through a long femoral sheath, a $6 \mathrm{~F}$ guiding catheter was advanced into the carotid artery. Vessel and aneurysm features were analyzed via biplane and 3D rotational angiography. Based on the aneurysm neck and parent artery diameter, a flow-diverter stent was chosen to allow enough wall apposition and coverage of the aneurysm neck. The stent was unsheathed under roadmap guidance through a 0.027 -inch microcatheter navigated beyond the aneurysm neck. Immediately postdeployment, VasoCT
(Philips Health care, Best, the Netherlands) with diluted iodinated contrast medium was used to assess stent apposition to the arterial wall.

\section{Clinical and Imaging Assessment}

Clinical evaluation was performed before, postprocedure, throughout the following days, and at discharge. The modified Rankin Scale was used for outcome assessment. Clinical follow-up evaluation was performed at 3, 6, 12, and 24 months. Usually, the degree of aneurysm occlusion was evaluated with MR angiography at 6 months and digital subtraction angiography at 12 and 24 months. Treatment outcomes were graded according to the O'Kelly-Marotta (OKM) grading scale ${ }^{16}$ based on the DSA images. The degree of filling $(\mathrm{A}=$ total, $\mathrm{B}=$ subtotal, $\mathrm{C}=$ entry remnant, $\mathrm{D}=$ no filling) and the degree of stasis (prolongation of stasis into $1=$ arterial, $2=$ capillary, $3=$ venous phase) were rated before stent deployment, immediately after, and during follow-up.

\section{Statistical Analysis}

Statistical analysis was performed with GraphPad QuickCalcs software (GraphPad Software, San Diego, California). Summary statistics are presented for all data available using means \pm SDs for continuous variables and frequency tabulations for categoric variables.

\section{RESULTS}

\section{Baseline Population Characteristics}

Population characteristics are summarized in On-line Table 1. In the 3-year period, 15 consecutive patients ( 10 women, 5 men; mean age, $60.9 \pm 10.5$ years; range, $40-77$ years) with 17 distal ACA aneurysms were included in this study. Pretreatment mRS was 0 for 4 patients (26.6\%), 1 for 6 patients (40\%), and 2 for 5 patients (33\%). Overall, 3 patients were hypertensive (20\%), 3 patients were smokers (20\%), 6 patients were hypertensive and smokers (40\%), and only 1 patient presented with a family history of aneurysmal subarachnoid hemorrhage (6\%).

\section{Aneurysm Characteristics}

All aneurysms were saccular with a mean size of $4.25 \pm 3.9 \mathrm{~mm}$; range, 2-9 mm. Five aneurysms (29\%) were medium-sized (5.0$9.9 \mathrm{~mm}$ ) (On-line Table 1). All reported aneurysms were localized in the distal portion of the ACA behind the anterior communicating artery. The aneurysms arose from the branching points of the cortical distal ACA branches. Accordingly, 3 aneurysms originated from the frontopolar division $(17.5 \%)$; 10 , from the callosomarginal division (59\%); 2 , from the anterior internal frontal artery division $(12 \%)$; 1 , from the middle internal frontal artery $(6 \%)$; and 1 , from the distal portion of the pericallosal artery (superior parietal artery) (6\%). Eleven aneurysms were unruptured (65\%), whereas $5(29 \%)$ were previously ruptured and treated with coil embolization in the acute phase. One ruptured aneurysm was discovered 3 weeks after rupture (patient 4) and was treated with flow diversion in the subacute phase. Among the unruptured group, 1 aneurysm (6\%) was previously coiled and treated with flow diversion because of recanalization (patient 3 ). Overall, 11 aneurysms had flow diverters as the first treatment (65\%); and 6, as the retreatment (35\%).

AJNR Am J Neuroradiol 39:1100-06 Jun 2018 www.ajnr.org 1101 

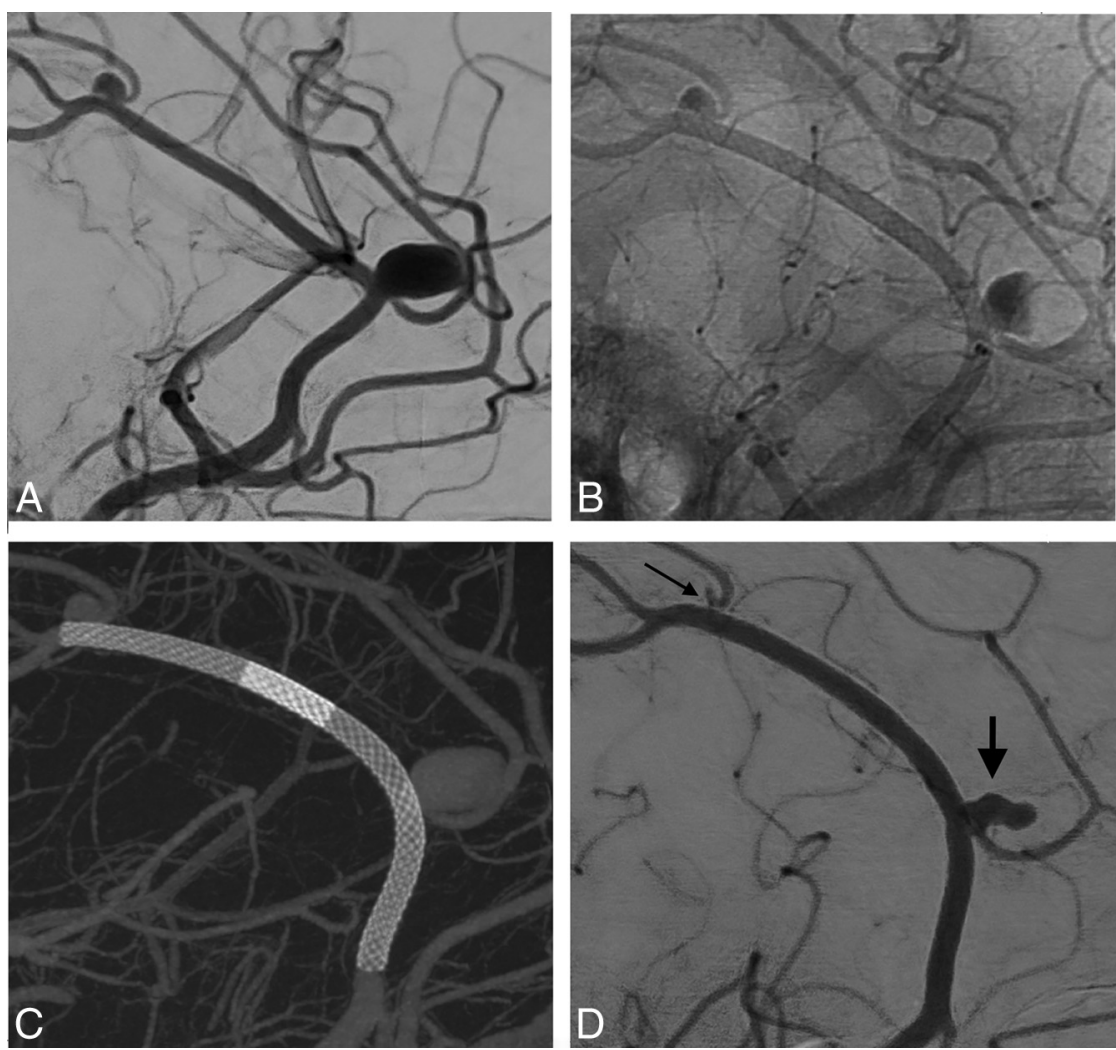

FIG 1. A, Left ICA angiography depicting 1 medium-sized aneurysm $(7 \times 9 \mathrm{~mm})$ located at the callosomarginal artery and 1 small aneurysm $(4 \times 3 \mathrm{~mm})$ located at the superior parietal artery bifurcation (patient 5). B, Flow stagnation immediately after the deployment of 2 telescopic PEDs $(25 \times 14$ $\mathrm{mm}+25 \times 20 \mathrm{~mm}$ ). C, Flat panel CT reconstruction shows successful stent implantation and correct vessel wall apposition. $D$, Eighteen-month DSA follow-up shows incomplete occlusion (short arrow) (OKM B2) and near-complete occlusion (long arrow) (OKM C2) of the aneurysms.

\section{Treatment Characteristics and Technical Results}

Overall, 12 aneurysms were treated with a Pipeline Embolization Device (PED; Covidien, Irvine, California); 3, with a Silk flowdiverter (Balt Extrusion, Montmorency, France); and 2, with a Flow-Redirection Endoluminal Device (FRED; MicroVention, Tustin, California). A single stent was used in all except 1 case (patient 5 with 2 aneurysms along the pericallosal artery was treated with 2 telescopic PEDs) (On-line Table 2). No multiple overlapping flow-diverter stents were used to cover the aneurysm neck.

In all cases, the stent was successfully navigated to the target area and deployed across the aneurysm neck. Correct stent apposition to the arterial wall was confirmed with VasoCT in all cases.

\section{Clinical Outcome and Procedure-Related Complications}

Treatment-related complications and clinical outcomes are summarized in On-line Table 2. Overall, 3 patients showed ischemic complications in the perioperative period. A minor transient stroke in the basal ganglia developed in the patient treated with 2 telescopic PEDs (patient 5) (Fig 1). This patient showed transient hemiparesis 24 hours after treatment. Immediate MR imaging demonstrated small embolic lesions in the basal ganglia. A dose adjustment of prasugrel from 10 to $20 \mathrm{mg}$ was performed (the patient was resistant to clopidogrel), and the patient was discharged without neurologic deterioration. There were 2 major strokes related to stent thrombosis. One patient (patient 11) (Fig 2), after discontinuation of the dual-antiplatelet therapy due to low compliance with the medical treatment, developed severe hemiparesis 10 days after treatment with the Silk stent. MR imaging and DSA showed intrastent thrombosis and pericallosal territory infarct. Due to the absence of the penumbra ischemic area evaluated with MR imaging, DWI, FLAIR, and PWI (the patient arrived at the hospital 20 hours after the onset of symptoms), no additional acute endovascular or medical treatments were performed. The patient was discharged with severe hemiparesis (mRS 4) and normal dual-antiplatelet therapy. The second patient (patient 13), treated with aspirin and clopidogrel, developed moderate right hemiparesis and a confused state due to acute FRED stent thrombosis 12 hours after treatment. The stent was completely recanalized after systemic abciximab injection, and the patient was discharged with a mild right-leg weakness. All patients were available at the long-term clinical follow-up (the mean clinical follow-up was 14 months; range, 3-24 months). All except 1 (patient 11) presented with an mRS score of 0-2 (93\%).

\section{Angiographic Outcome of Aneurysms}

The mean radiologic follow-up was 12.6 months (range, 3-24 months) (On-line Table 2). Fourteen patients and 16 aneurysms were available for the long-term angiographic follow-up. Overall, 12 (75\%) aneurysms were completely occluded (OKM score D) (Fig 3), 1 aneurysm (6\%) showed nearcomplete occlusion (OKM score C), and 3 aneurysms (19\%) were incompletely occluded (OKM score B). The mean radiologic follow-up among the group of aneurysms with complete/near-complete occlusion (OKM C2-D) was higher compared with the group with incomplete occlusion (OKM B) (13.5 versus 7 months, $P=.014)$. All 6 aneurysms previously coiled were completely occluded after flow diversion (OKM score D), whereas 7 of the 10 aneurysms treated with flow diverters alone showed complete/near-complete occlusion (OKM C-D) during follow-up $(P=.4)$. The incidence of hypertension and smoking was $54 \%$ and $50 \%$ among the group of completely occluded and incompletely occluded aneurysms, respectively. There were no cases of aneurysm rupture, in-stent occlusion, or retreatment during long-term follow-up. Three cases of asymptomatic mild stent stenosis $(<50 \%)$ were observed and were related to in-stent intimal hyperplasia. In case of mild stent stenosis, aspirin was continued after the 1-year follow-up.

\section{Angiographic Outcome of Covered Branches}

Angiographic outcomes of jailed branches are summarized in Online Table 2. Immediately after stent deployment, there were no 

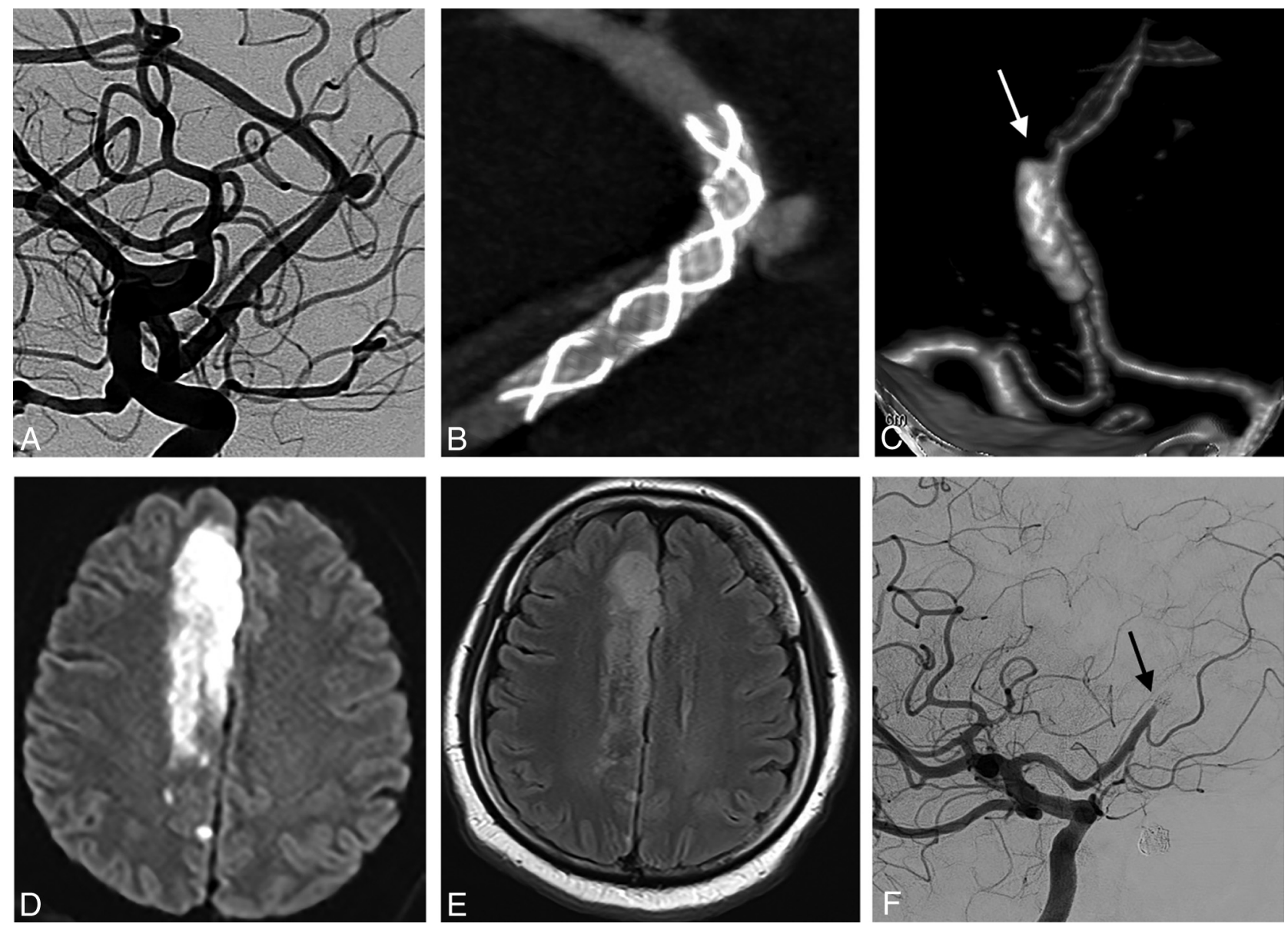

FIG 2. A, Patient 11 with a right $3 \times 3 \mathrm{~mm}$ aneurysm originating from the callosomarginal bifurcation. $B$, Flat panel CT scan confirms correct vessel wall apposition of a single Silk $(2 \times 15 \mathrm{~mm})$ stent. Ten days after treatment, due to inadvertent discontinuation of the dual-antiplatelet therapy, the patient was admitted to the emergency department with severe left hemiparesis $(C)$. An urgent brain $C T$ angiography shows occlusion of the right A2 distal to the stent (white arrow). D, Diffusion-weighted MR imaging detects an acute ischemic lesion on the territory of the right pericallosal artery. E, Because of the FLAIR positive for lesions (the patient arrived at the hospital 20 hours after the onset of the symptoms), no acute medical and endovascular treatments were performed. F, DSA was performed to confirm the complete stent occlusion (black arrow). The patient was discharged with severe left hemiparesis (mRS 4) and dual-antiplatelet therapy.

cases of arterial narrowing or flow changes of covered branches. Asymptomatic branch narrowing was observed in 3 patients during angiographic follow-up (20\%). No cases of branch occlusion were diagnosed.

\section{DISCUSSION}

Our study demonstrates that flow-diversion treatment of small distal ACA aneurysms is effective with rates of complete and nearcomplete occlusion close to $81 \%$. Flow diversion plus coiling, in retreatment of lesions previously coiled, allowed higher rates of occlusion (100\%) compared with flow diverters alone (70\%). Aneurysms arising from the distal ACA often presented with a wideneck configuration that may necessitate double microcatheterization for stent-assisted coiling or balloon remodeling. However, dual-microcatheter manipulation in small arteries is challenging and can predispose the patient to increased risk of complications. ${ }^{8}$ In our experience, the procedure was successful in all cases and appears to be a straightforward treatment option for lesions difficult to treat with conventional endovascular strategy. However, patients should be carefully selected due to the not negligible rate of perioperative ischemic events, with $13 \%$ permanent neurologic complications.

\section{Angiographic Outcome}

To the best of our knowledge, our study is the largest to date that specifically focused on the flow-diversion treatment of distal ACA aneurysms. Regarding the occlusion rates, our results are in line with those reported in previous studies that focused on distal aneurysm location. De Macedo Rodrigues et $\mathrm{al}^{8}$ reported 70\% complete occlusion of pericallosal aneurysms treated with PED devices. Similarly, other series reported rates of distal ACA aneurysm occlusion between $60 \%$ and $100 \%$ after flow-diverter stent deployment (On-line Table 3). ${ }^{6-15}$ The flow redirection that allows aneurysm thrombosis and neck endothelization is in relation to local stent porosity that is influenced by stent sizing. Undersized stents are associated with a shorter deployment, more condensed pores, and higher mesh density, resulting in an increased flow-diversion effect. ${ }^{17,18}$ In our series, the mean diameters of the proximal and distal portions of the parent artery were approximately 1.8 and $1.6 \mathrm{~mm}$, respectively. The diameter of the devices used ranged between 2 and $2.75 \mathrm{~mm}$ (On-line Table 2), resulting in stent oversizing, subsequent device elongation, and relative reduction of metal stent coverage. Despite the theoretic reduction of the flow diversion, the effect of the stent was enough to allow high rates of aneurysm occlusion. However, a subgroup of analysis 

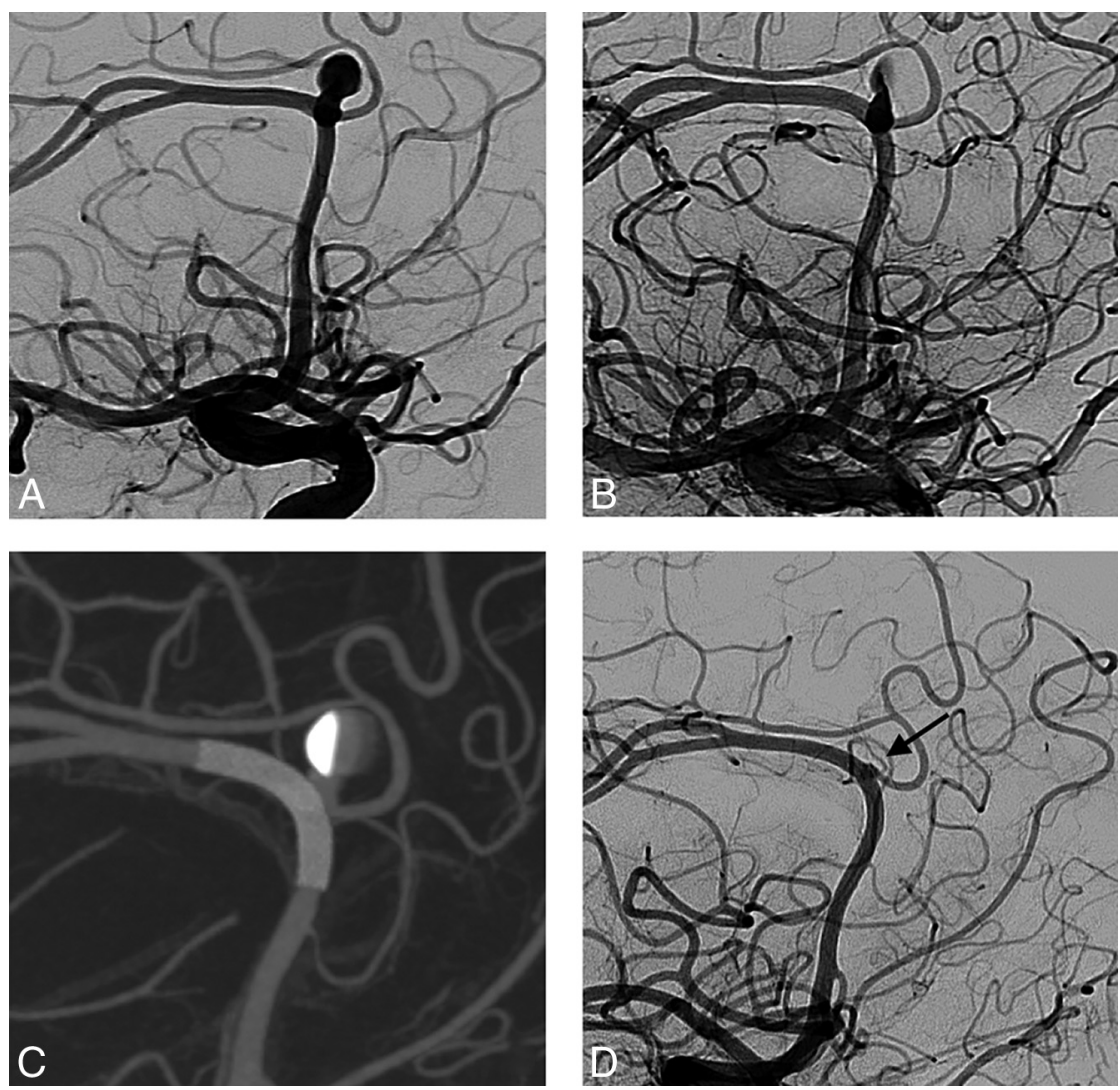

FIG 3. A, Patient 4 with a small left $A 2 / A 3$ aneurysm located at the callosomarginal artery bifurcation. After an attempted coil embolization, due to the instability of the microcatheter inside the aneurysm (related to the tortuosity of the aortic arch and the cervical ICA), the aneurysm was treated with a flow-diverter stent. B, Flow stagnation immediately after deployment of a single PED $(2.5 \times 14 \mathrm{~mm})$. C, Postintervention flat panel CT reconstruction shows adequate aneurysm neck coverage and proper vessel wall apposition. $D$, Twelve-month DSA follow-up shows complete occlusion of the aneurysm (black arrow).

showed that flow diversion plus coiling that was used for retreatment of lesions previously coiled allowed higher rates of occlusion (100\%) compared with flow diverters alone (70\%). This finding is in accordance with those of previous series comparing flow diverters alone versus flow diverter plus coiling.

Lin et $\mathrm{al}^{19}$ reported higher rates of complete aneurysm occlusion among the group of aneurysms treated with PED plus coils, compared with those treated with flow diverters alone $(93.1 \%$ versus $74.7 \%, P=.03$ ). Accordingly, one of the shortcomings of this technique when the retreatment is required is the necessity of a second overlapped flow diverter with a higher risk of ischemic events, considering the small diameter of the parent artery. However, we found that the mean radiologic follow-up among the group of aneurysms showing adequate occlusion (OKM C2-D) was significantly higher compared with the group with incomplete occlusion (OKM B) (13.5 versus 7 months, $P=.014)$ and showed that the length of follow-up can influence the aneurysm occlusion rate.

Although flow diversion allows a high rate of angiographic success, there are important concerns regarding possible occlusion of covered side branches. Theoretically, the pressure gradient across the jailed branch is reduced, and the artery can be occluded if the flow competition from the collateral circulation is wellrepresented. ${ }^{20}$ Few studies focused on the flow remodeling of dis- tal branches covered with flow-diverter stents. A recent meta-analysis of middle cerebral artery aneurysms treated with flow diversion showed $10 \%$ occlusion of covered MCA branches and 25\% arterial narrowing or slow flow. ${ }^{21}$ When we investigated the literature, the rate of flow modification of covered branches coming from the distal ACA ranges between $20 \%$ and $40 \%$, with the absence of related symptoms. ${ }^{6-15}$ Nossek et al ${ }^{12}$ reported 1 asymptomatic (20\%) A2 branch occlusion after treatment with 2 overlapping PEDs. Similarly, De Macedo Rodrigues et $\mathrm{al}^{8}$ reported $40 \%$ asymptomatic narrowing of jailed callosomarginal arteries during follow-up (On-line Table 3). Our series confirmed the high rate of flow modification in jailed branches originating from the distal ACA. We found $20 \%$ asymptomatic arterial narrowing after treatment with a single flow-diverter stent ( 2 callosomarginal arteries and 1 frontopolar artery), whereas no cases of occlusion were detected.

\section{Treatment-Related Complications}

When we investigated the literature, the overall incidence of complications in series reporting distal aneurysms treated with flow-diverter stents ranged between $15 \%$ and $20 \%$, with approximately $10 \%$ permanent neurologic deficits. $^{9,10,21,22}$ In a recent series of 42 patients treated with FRED devices deployed in small and distal vessels $(2-3 \mathrm{~mm})$, the overall rate of ischemic complications was close to $11 \%$ and the incidence of ischemic events among patients with distal ACA was nearly $10 \% .{ }^{11}$ However, in other recent studies of distal ACA aneurysms treated with the PED, the authors reported no complications related to the procedure. ${ }^{6-10,12,13}$ In our experience, we had $6 \%$ (patient 5) transient complication, and $13 \%$ permanent complications (patients 11 and 13), and all were related to ischemic events in the perioperative period. One patient experienced ischemic events consequent to an insufficient platelet inhibition level (patient 5), and the other one, due to nonadherence with the antiplatelet therapy (patient 11). Accordingly, these findings underline the close relationship among ischemic injury, in-stent thrombosis, and antiplatelet function in the flow-diversion treatment of aneurysms located in small and distal vessels.

Complication rates for endovascular treatment of distal ACA aneurysms also remain a concern for the coiling, stent-assisted coiling, and balloon-remodeling techniques. Sturiale et $\mathrm{al}^{23}$ reported $20 \%$ complications related to the treatment of 20 distal ACA aneurysms with coiling and stent-assisted coiling. In addition, when we reviewed the literature, the endovascular perioperative complications rate was close to $12 \%$, with a procedure-re- 
lated morbidity of $8 \% .^{23}$ In a recent meta-analysis, neurologic morbidity and mortality rates were $15 \%$ and $9 \%$ after an operation, and $14 \%$ and $7 \%$ after endovascular treatment of distal ACA aneurysms. ${ }^{24}$

Recently, flow diversion with low-profile braided stents, as stent monotherapy, has been reported as an alternative option for the treatment of small and distally located intracranial aneurysms not amenable to conventional endovascular techniques. Aydin et $\mathrm{al}^{25}$ described a series of 20 distal aneurysms treated with LEO Baby devices (LEO+Baby; Balt Extrusion) that were used as mini flow-diversion stents, reporting $73 \%$ total occlusion and 5\% treatment-related complications.

\section{Limitations of the Study}

Our study has limitations intrinsic to single-center series, and it is not a population-based study. The number of patients was relatively small, though larger than other reported case series. The data, although prospectively collected, were analyzed retrospectively. In addition, the imaging outcome was assessed by operators and not independently. There was a lack of standardization of radiologic follow-up.

\section{CONCLUSIONS}

Treatment of distal anterior cerebral artery aneurysms with flowdiverter stents is effective, allowing high rates of aneurysm occlusion. Flow diversion plus coiling in the retreatment of lesions previously coiled allowed higher rates of occlusion, compared with flow diverters alone. In addition, the strategy appears straightforward and technically feasible. However, the risk of ischemic complications is not negligible, and flow-diversion treatment should be evaluated only for aneurysms not amenable to simple coil embolization.

\section{ACKNOWLEDGMENTS}

We thank Professor Beth De Felici for the English revision.

Disclosures: Federico Cagnazzo-UNRELATED: Employment: University of Florence.* Pierre-Henri Lefevre-UNRELATED: Consultancy: Medtronic, Stryker. Alain Bonafe-UNRELATED: Consultancy: Stryker, Medtronic, MicroVention. Vincent Costalat-UNRELATED: Consultancy: Stryker, Medtronic; Grants/Grants Pending: Stryker, Medtronic*; Payment for Development of Educational Presentations: Medtronic, Stryker, Balt Extrusion. *Money paid to the institution.

\section{REFERENCES}

1. Hernesniemi J, Tapaninaho A, Vapalahti M, et al. Saccular aneurysms of the distal anterior cerebral artery and its branches. Neurosurgery 1992;31:994-98; discussion 998-99 CrossRef Medline

2. Perlmutter D, Rhoton AL Jr. Microsurgical anatomy of the distal anterior cerebral artery. J Neurosurg 1978;49:204-28 CrossRef Medline

3. Waldenberger P, Petersen J, Chemelli A, et al. Endovascular therapy of distal anterior cerebral artery aneurysms-an effective treatment option. Surg Neurol 2008;70:368-77 CrossRef Medline

4. Cavalcanti DD, Abla AA, Martirosyan NL, et al. Endovascular management of distal ACA aneurysms: single-institution clinical experience in 22 consecutive patients and literature review. AJNR Am J Neuroradiol 2013;34:1593-99 CrossRef Medline

5. Hui FK, Schuette AJ, Moskowitz SI, et al. Microsurgical and endovascular management of pericallosal aneurysms. J Neurointerv Surg 2011;3:319-23 CrossRef Medline
6. Clarençon F, Di Maria F, Gabrieli J, et al. Flow diverter stents for the treatment of anterior cerebral artery aneurysms: safety and effectiveness. Clin Neuroradiol 2017;27:51-56 CrossRef Medline

7. Dabus G, Grossberg JA, Cawley CM, et al. Treatment of complex anterior cerebral artery aneurysms with Pipeline flow diversion: mid-term results. J Neurointerv Surg 2017;9:147-51 CrossRef Medline

8. De Macedo Rodrigues K, Kühn AL, Tamura T, et al. Pipeline embolization device for pericallosal artery aneurysms: a retrospective single center safety and efficacy study. Oper Neurosurg (Hagerstown) 2018;14:351-58 CrossRef Medline

9. Lin N, Lanzino G, Lopes DK, et al. Treatment of distal anterior circulation aneurysms with the Pipeline embolization device: a US multicenter experience. Neurosurgery 2016;79:14-22 CrossRef Medline

10. Martínez-Galdámez M, Romance A, Vega P, et al. Pipeline endovascular device for the treatment of intracranial aneurysms at the level of the circle of Willis and beyond: multicenter experience. J Neurointerv Surg 2015;7:816-23 CrossRef Medline

11. Möhlenbruch MA, Kizilkilic O, Killer-Oberpfalzer M, et al. Multicenter experience with FRED Jr flow re-direction endoluminal device for intracranial aneurysms in small arteries. AJNR Am J Neuroradiol 2017;38:1959-65 CrossRef Medline

12. Nossek E, Zumofen DW, Setton A, et al. Treatment of distal anterior cerebral artery aneurysms with the Pipeline embolization device. J Clin Neurosci 2017;35:133-38 CrossRef Medline

13. Pistocchi S, Blanc R, Bartolini B, et al. Flow diverters at and beyond the level of the circle of Willis for the treatment of intracranial aneurysms. Stroke 2012;43:1032-38 CrossRef Medline

14. Puri AS, Massari F, Asai T, et al. Safety, efficacy, and short-term follow-up of the use of Pipeline embolization device in small $(<2.5 \mathrm{~mm}$ ) cerebral vessels for aneurysm treatment: single institution experience. Neuroradiology 2016;58:267-75 CrossRef Medline

15. Vachhani JA, Nickele CM, Elijovich L, et al. Flow diversion for treatment of growing $A 2$ aneurysm in a child: case report and review of flow diversion for intracranial aneurysms in pediatric patients. World Neurosurg 2016;96:607.e613-607.e617 CrossRef Medline

16. O'Kelly CJ, Krings T, Fiorella D, et al. A novel grading scale for the angiographic assessment of intracranial aneurysms treated using flow diverting stents. Interv Neuroradiol 2010;16:133-37 CrossRef Medline

17. Shapiro M, Raz E, Becske T, et al. Variable porosity of the Pipeline embolization device in straight and curved vessels: a guide for optimal deployment strategy. AJNR Am J Neuroradiol 2014;35:727-33 CrossRef Medline

18. Berg P, Iosif C, Ponsonnard S, et al. Endothelialization of overand undersized flow-diverter stents at covered vessel side branches: an in vivo and in silico study. J Biomech 2016;49:4-12 CrossRef Medline

19. Lin N, Brouillard AM, Krishna C, et al. Use of coils in conjunction with the Pipeline embolization device for treatment of intracranial aneurysms. Neurosurgery 2015;76:142-49 CrossRef Medline

20. Saleme S, Iosif C, Ponomarjova S, et al. Flow-diverting stents for intracranial bifurcation aneurysm treatment. Neurosurgery 2014; 75:623-31; quiz 631 CrossRef Medline

21. Cagnazzo F, Mantilla D, Lefevre PH, et al. Treatment of middle cerebral artery aneurysms with flow-diverter stents: a systematic review and meta-analysis. AJNR Am J Neuroradiol 2017;38:2289-94 CrossRef Medline

22. Gawlitza M, Januel AC, Tall P, et al. Flow diversion treatment of complex bifurcation aneurysms beyond the circle of Willis: a single-center series with special emphasis on covered cortical branches and perforating arteries. J Neurointerv Surg 2016;8:481-87 CrossRef Medline 
23. Sturiale CL, Brinjikji W, Murad MH, et al. Endovascular treatment of distal anterior cerebral artery aneurysms: single-center experience and a systematic review. AJNR Am J Neuroradiol 2013;34: 2317-20 CrossRef Medline

24. Petr O, Coufalová L, Bradáč O, et al. Safety and efficacy of surgical and endovascular treatment for distal anterior cerebral artery aneurysms: a systematic review and meta-analysis. World Neurosurg 2017;100:557-66 CrossRef Medline

25. Aydin K, Barburoglu M, Sencer S, et al. Flow diversion with lowprofile braided stents for the treatment of very small or uncoilable intracranial aneurysms at or distal to the Circle of Willis. AJNR Am J Neuroradiol 2017;38:2131-37 CrossRef Medline 